\title{
Tradução e adaptação de mangás: uma prática linguístico-cultural
}

\author{
Rafael Schuabb Poll da Fonseca*
}

Resumo: A tradução, cuja relevância foi ressaltada por JAKOBSON (1975) e FLUSSER (2002), tem sua importância cada vez mais reconhecida e, por isso, vem conquistando mais espaço nos campos de pesquisa linguísticos. A tarefa de traduzir é muito mais complexa do que simplesmente um mero escambo linguístico, uma simples troca de sinônimos entre línguas. 0 avanço dos estudos de tradução aliado à imponência do mercado japonês de histórias em quadrinhos e à sua infiltração no mercado editorial brasileiro são os dois grandes justificadores de minha pesquisa, que busca compreender a mecânica da tradução e da adaptação de mangás, através da exposição e análise dos seus principais obstáculos, enumerados por Arnaldo Oka, tradutor-chefe da Editora JBC, em palestra realizada no XIX Encontro Nacional de Professores Universitários de Língua, Literatura e Cultura J aponesa.

Palavras-chave: Tradução; Adaptação; Mangá; Intercâmbio cultural.

Abstract: The translation, which importance was emphasized by JAKOBSON (1975) and FLUSSER (2002), has its importance increasingly recognized and therefore is gaining more space in the fields of linguistic research. The task of translating is much more complex than just a mere barter language, a simple exchange of synonyms between languages. The advancement of translation studies allied to grandeur of the Japanese market for mangas and their infiltration into the Brazilian publishing market are the two great apologists of my research, which seeks to understand the mechanics of translation and adaptation of mangas, through exposure and analysis its main obstacles, listed by Arnaldo Oka, chief translator of the JBC Publisher, at the XIX Encontro Nacional de Professores Universitários de Língua, Literatura e Cultura Japonesa.

Keywords: Translation; Adaptation; Manga; Cultural exchange.

\footnotetext{
Formado em Letras Português/Japonês e mestrando de Linguística na UERJ. Email: rafaelschuabb@gmail.com.
} 

Fonseca, Rafael Schuabb Poll da - Tradução e adaptação de mangás: uma prática linguístico-cultural

\section{Introdução}

As histórias em quadrinhos japonesas, os mangás, encontravam-se praticamente restritas ao arquipélago nipônico até vinte anos atrás, quando finalmente atravessaram o oceano e chegaram ao Ocidente, após o sucesso crescente dos desenhos animados japoneses - muitos deles, é necessário ressaltar, baseados em mangás - nos países da Europa e da América. Hoje, o Japão mantém o maior mercado editorial do mundo, em grande parte por conta do mercado de mangás, que também é o maior de histórias em quadrinhos.

As características peculiares dos mangás, por exemplo, os desenhos em preto e branco e as histórias geralmente finitas, são muito diferentes da maioria das histórias em quadrinhos ocidentais, como é o caso de Batman, Turma da Mônica etc. Embora causem um estranhamento inicial ao leitor acostumado com os quadrinhos do Ocidente, essas particularidades dos mangás conseguiram conquistar uma legião de fãs ocidentais a partir do final da década de 80 e, especificamente no Brasil, no fim do século XX.

Os mangás, enquanto produtos artísticos japoneses, refletem a cultura nipônica e, por isso, se tornaram o principal meio de divulgação dessa cultura no Ocidente. Por meio dessas obras, os leitores podem se aproximar de elementos como a moda, hábitos, gestos, humor, lições de etiqueta, moral e a rica e extensa história japonesa (injustamente ignorada pelo currículo escolar brasileiro). Os mangás conseguiram cativar os leitores do outro lado do mundo, apesar de serem fortemente marcados por uma cultura tão diferente da ocidental.

O termo "traduzir" vem do latim traducere, que significa "levar de um lugar para outro" (BERNARDO 2002: 43). É justamente sobre o profundo abismo cultural que separa o Ocidente do Oriente que o tradutor/adaptador de histórias em quadrinhos japonesas precisa se deslocar, de um lado para outro, em sua prática profissional. 
Fonseca, Rafael Schuabb Poll da - Tradução e adaptação de mangás: uma prática linguístico-cultural

A tarefa de traduzir é muito mais complexa do que simplesmente um mero escambo linguístico, em que se trocam palavras por aparentes sinônimos em outra língua. Um texto bem traduzido é aquele em que foram feitas as adaptações linguístico-culturais necessárias para que ele tenha o mesmo impacto e significância que apresentou diante do leitor da versão em língua original.

A tradução vem tendo a sua importância cada vez mais reconhecida e, por isso, cada vez mais ganha espaço nos campos de pesquisa linguísticos. 0 avanço dos estudos de tradução, aliado à imponência do mercado de quadrinhos japonês e à sua infiltração no mercado editorial brasileiro, justificam o presente trabalho, que se revela necessário para compreender melhor a mecânica da tradução e da adaptação, processos envolvidos em toda publicação de mangás no Brasil e que são, certamente, determinantes para o sucesso dessa mídia.

\section{História do mangá}

A arte japonesa, assim como sua cultura, caracterizou-se por se desenvolver de forma independente dos outros países, já que o Japão, por muito tempo, manteve-se fechado para o restante do mundo. Os contatos ocasionais, porém, nunca foram desperdiçados, afinal, os japoneses sempre souberam reconhecer o que havia de bom na cultura alheia e aplicá-la de modo particular e otimizado em sua própria cultura.

Pode-se dizer que uma maior troca de influências só aconteceu a partir de 1853, quando navios americanos forçaram o Japão a se abrir para o comércio internacional. Desde então, a influência ocidental floresceu em todos os aspectos da cultura, como, por exemplo, nas próprias histórias em quadrinhos. 
Fonseca, Rafael Schuabb Poll da - Tradução e adaptação de mangás: uma prática linguístico-cultural

É complicado definir onde e quando apareceram os primeiros quadrinhos no mundo, já que eles nem sempre tiveram uma forma definida como hoje em dia. Porém, a primeira história em quadrinhos tal como conhecemos hoje em dia só surgiu nos Estados Unidos, em 1894, com a publicação das tiras Yellow Kid na revista Truth, que criou e definiu os primórdios da linguagem de quadrinhos (NeTO 2009: 15).

No Japão, por outro lado, as xilogravuras são vistas como precursoras dos mangás (LUYTEN 2001-2002: 91-100). 0 próprio termo "mangá" tornou-se mais conhecido com a publicação da coleção de ilustrações em xilogravura Hokusai Manga, de Katsuhika Hokusai, mais famoso pela pintura A Grande Onda de Kanagawa.

A definição de mangá tal qual é usada atualmente só surgiria por meio de Rakuten Kitazawa, um dos primeiros quadrinistas japoneses, no início do século XX. Naquela época, os mangás eram publicados em formato de tiras em jornais ou revistas de humor, seguindo um modelo em ascensão na Europa e nos Estados Unidos, e alcançaram certo sucesso no Japão.

Entretanto, as frequentes guerras travadas pelos japoneses contra outros países e os prejuízos decorrentes delas praticamente extinguiram a produção local de histórias em quadrinhos. Com os desastres oriundos das guerras, como a Guerra Sino-Japonesa e as duas Guerras Mundiais, o país encontrava-se em ruínas tanto no aspecto material quanto psicológico ao final de 1945. Os japoneses saíram derrotados da Segunda Guerra Mundial, tendo inclusive sofrido dois ataques de bomba atômica em seu território. Os fortes problemas econômicos e sociais, distribuídos entre um povo conhecido pelo seu forte orgulho, acabaram gerando comportamentos e hábitos até hoje refletidos na cultura local, como pode ser observado nos mangás.

Um deles é o fazer muito com pouco, que se refletiu nos mangás. Após a Guerra, a produção de quadrinhos voltou timidamente, com obras publicadas em papel de baixa qualidade. Sendo uma opção barata de entretenimento, era uma das poucas formas encontradas pela população local 
Fonseca, Rafael Schuabb Poll da - Tradução e adaptação de mangás: uma prática linguístico-cultural

para se distanciar dos problemas pelos quais o Japão estava passando e se divertir um pouco, o que acabou favorecendo a indústria nipônica de quadrinhos.

A linguagem e o charme dos mangás formariam um estilo particular a partir do final da década de 40, quando Osamu Tezuka, natural de Osaka, começou a chamar a atenção dos japoneses com a obra Shin Takarajima (A Nova Il ha do Tesouro, em português). Buscando inspirações nas animações de Walt Disney e de Max Fleischer (de Betty Boop e Popeye), às quais teve acesso por meio de seu pai durante a infância, o jovem Tezuka, de apenas 19 anos, incorporou a linguagem do cinema no papel, utilizando ângulos ousados e temas mais profundos que o simples humor barato.

A partir desse momento, o mercado de quadrinhos do Japão cresceu vigorosamente sem qualquer influência ou presença no mercado externo. Grandes editoras americanas de quadrinhos como a Marvel Comics (de X-Men, Vingadores e Homem-Aranha, entre outros) até tentaram introduzir algumas de suas séries de sucesso no Japão, mas foram esmagadas pela avalanche de títulos locais, de maior apelo entre os japoneses.

Apesar do sucesso de alguns desenhos animados japoneses (os chamados animês) no Ocidente, ainda era praticamente nula a publicação de mangás nos continentes americano, europeu e até mesmo em outros países da Ásia. Isso mudou com o sucesso de Akira, filme de 1988, baseado em mangá homônimo. Retratando uma Tóquio futurista e pós-apocalíptica, o longametragem em animação chamou a atenção dos americanos e europeus para a estética e conteúdo dos quadrinhos e desenhos animados japoneses.

Isso foi ainda mais acentuado com o advento da internet, que possibilitou uma melhor divulgação dos mangás e animês a uma legião de fãs muito mais abrangente que os pequenos grupos que existiam até então. A digitalização e compartilhamento de obras pela internet, geralmente traduzidas, mesmo que de forma polemicamente ilegal, ajudou a difundir essa nova arte nos mercados estrangeiros. A diversidade de gêneros também atraiu 
Fonseca, Rafael Schuabb Poll da - Tradução e adaptação de mangás:

uma prática linguístico-cultural

pessoas que não liam quadrinhos por não se identificarem com as histórias de super-heróis americanos. Isso inclui o público feminino, que foi encontrar nos mangás histórias produzidas especialmente para elas.

\section{Mangás no Brasil}

No Japão, “manga” é o termo utilizado para designar qualquer história em quadrinhos, produzida dentro ou fora do Japão. Em kanji, “manga” é escrito “漫画”, sendo o primeiro kanji de “involuntário” e o segundo de “desenho”, “imagem”. No Brasil, porém, “mangá”, com acento agudo no segundo "a", é o termo utilizado para designar exclusivamente histórias em quadrinhos feitas no Japão. ${ }^{1}$

A publicação de mangás no Brasil ocorreu apenas no final dos anos 80 e início dos 90 do século XX, com séries como Lobo Solitário (pela editora Cedibra, em 1988, e depois pela Sampa, em 1990); Akira (Globo, em 1990); Mai - Garota Sensitiva (Abril, em 1992); Crying Freeman (Sampa, em 1992); e A Lenda de Kamui (Abril, em 1993). Todos esses mangás haviam sido publicados antes nos Estados Unidos e suas edições brasileiras eram traduzidas da versão em inglês, ou seja, eram traduções de traduções.

As histórias em quadrinhos japonesas praticamente sumiram do mercado editorial brasileiro por quase uma década. As duas editoras responsáveis pela popularização dos mangás, que ocorreu na virada do século XX para o XXI, no Brasil foram a Conrad (com Cavaleiros do Zodíaco e Dragon

\footnotetext{
${ }^{1}$ A definição de "mangá" utilizada no Brasil gera um certo preconceito por parte dos leitores em relação a obras nacionais que apresentam características dos quadrinhos japoneses, mas que esses consumidores não aceitam como tais. A alegação é a de que "mangá" é uma história em quadrinhos produzida no Japão, por japoneses e que, portanto, reflete a cultura nipônica. Porém, uma vez que no próprio Japão o termo "mangá" pode ser utilizado para quadrinhos estrangeiros, eu discordo desses fãs mais puristas e acredito que o conceito de "mangá" está muito mais ligado à linguagem e à estética do que ao local de nascimento do quadrinista em questão.
} 
Fonseca, Rafael Schuabb Poll da - Tradução e adaptação de mangás: uma prática linguístico-cultural

Ball) e a JBC (com Samurai X, Sakura Card Captors, Video Girl Ai e Guerreiras Mágicas de Rayearth).

O sucesso dos mangás nesse período era tanto que Dragon Ball, da Conrad, ganhou até mesmo um prêmio da distribuidora DINAP (Distribuidora Nacional de Publicações), pelo fato de que essa história em quadrinhos ultrapassara os 100.000 exemplares vendidos de uma única edição. ${ }^{2}$

Os leitores de mangás estão cada vez mais exigentes e a fidelidade à edição original japonesa se tornou o grande diferencial, com a manutenção de elementos como a leitura em sentido oriental - da direita para a esquerda - e as páginas em preto e branco.

Outra exigência em relação à fidelidade de um mangá publicado no Brasil diz respeito ao seu número de páginas. Os primeiros mangás lançados no Brasil na virada do século eram, em sua maioria, publicados em versão de meio tankoubon (edição encardernada japonesa de uma única série de mangá), ou seja, com cerca de 100 páginas. Porém, com o passar do tempo, tornou-se cada vez mais comum as edições brasileiras que correspondem a um tankoubon inteiro, como é o caso de Battle Royale (da editora Conrad), Sunadokei (da Panini) e Hikaru no Go (da JBC), ou seja, com cerca de 200 páginas.

Mas nem tudo é motivo de comemoração na história da publicação de mangás no Brasil. A Conrad, uma das responsáveis pelo boom dos quadrinhos japoneses no país, acabou perdendo muito de sua credibilidade ao cancelar ${ }^{3}$ diversas séries de mangás, entre elas as famosas Vagabond e Dr. Slump. Por outro lado, muitas editoras apostaram nesse mercado, sendo o exemplo de maior sucesso a Panini. Apesar do início turbulento com a publicação de Angel Sanctuary, cuja edição a princípio desagradou os fãs, a Panini se impôs com

\footnotetext{
${ }^{2}$ Segundo o antigo editor executivo da Conrad, Sidney Gusman, "Dragon Ball chegou a vender 115 mil exemplares por quinzena" (Conexão Aluno, http://www.conexaoaluno.rj.gov.br/ especiais-17b.asp, acessado em 07/05/2010).

${ }^{3} \mathrm{Na}$ verdade, a editora Conrad não reconhece oficialmente que cancelou seus mangás, mas é o que parece para os consumidores. Por exemplo, o último volume que a editora lançou de Dr. Slump data do ano 2003.
} 
Fonseca, Rafael Schuabb Poll da - Tradução e adaptação de mangás: uma prática linguístico-cultural

trabalhos de qualidade e títulos de grande apelo junto aos consumidores, como Naruto, atualmente publicado pela editora.

\section{$3(\operatorname{Im})$ Possibilidade da tradução}

O grande desenvolvimento dos meios de comunicação e de transportes nas últimas décadas serviu como elemento catalisador para as relações entre os países e para a busca cada vez mais emergencial pela informação. Nesse contexto, em um mundo dito globalizado, os tradutores são profissionais absolutamente indispensáveis. Dessa forma, a área dos Estudos da Tradução vem obtendo cada vez mais espaço no meio acadêmico, conquistando, assim, seu lugar específico dentro dos estudos da Linguística (BerNARDo 2002: 15), segundo Maria Aparecida Salgueiro, então coordenadora do Escritório Modelo de Tradução Ana Cristina César do IL/UERJ.

A importância dos Estudos da Tradução também é validada por Roman Jakobson, um dos expoentes do Funcionalismo, ao afirmar que "a prática generalizada da comunicação interlingual, em particular, as atividades de tradução, devem ser objeto de atenção constante da ciência linguística" (JAKOBSON 1975: 66).

O estudioso do Círculo Linguístico de Praga aprofunda o conceito de tradução e o eleva a um patamar muito mais abrangente do que prega o senso comum. Na obra Linguística e Comunicação, o autor afirma que

o significado das palavras (...) é decididamente um fato linguístico - ou para sermos mais precisos e menos restritos - um fato semiótico e que o significado de um signo linguístico não é mais que sua tradução por um outro signo que the pode ser substituído, especialmente um signo "no qual ele se ache desenvolvido de modo mais completo" como insistentemente afirmou Peirce (JAKOBSON 1975: 63-64). 
Fonseca, Rafael Schuabb Poll da - Tradução e adaptação de mangás: uma prática linguístico-cultural

A partir de tais afirmações, pode-se concluir que Jakobson considera como tradução qualquer processo de interpretação de um signo.

Partindo desse pressuposto, o linguista propõe a tradução como um conceito tricotômico, enumerando as três maneiras de interpretação de um signo verbal, ou seja, de traduzir um signo. São elas: a tradução intralingual, que segundo Jackobson é a "interpretação dos signos verbais por meio de outros signos da mesma língua"; a tradução interlingual, ou seja, a "interpretação dos signos verbais por meio de alguma outra língua" - que seria a tradução propriamente dita -; e a tradução intersemiótica, que nada mais do que a "interpretação dos signos verbais por meio de sistemas de signos não-verbais" (idem: 64-65).

É importante ressaltar que o próprio Jackobson considera que não há uma equivalência perfeita entre sinônimos de signos tanto dentro de uma única língua quanto quando duas línguas são comparadas e que, por esse motivo, diz ele, "uma palavra (...) só pode ser plenamente interpretada por meio de uma combinação equivalente de unidades de código"” (idem: 65).

Contudo, como na tradução interlingual não se deve priorizar a simples troca de um signo por seu correspondente literal em outra língua, mas, sim, a substituição de uma mensagem por outra que the seja equivalente semanticamente na língua-meta, ${ }^{5}$ a imprecisão da sinonímia não é um fator que invalida esse tipo de interpretação de signos, ${ }^{6}$ uma vez que a língua-meta sempre conseguirá moldar os recursos de que dispõe para interpretar uma nova experiência cognitiva.

\footnotetext{
${ }^{4}$ Jakobson exemplifica a imperfeição da sinonímia entre línguas com a palavra portuguesa "queijo", que não pode ser inteiramente identificada a seu heterônimo em russo corrente, "syr", porque o requeijão é um queijo, mas não um "syr". (...) Em russo corrente, o alimento feito de coágulo espremido só se chama "syr" se for usado fermento.

${ }^{5}$ Língua-meta é o termo pelo qual o escritor Vilém Flusser se refere à língua para a qual se pretende traduzir um texto.

${ }^{6}$ Além disso, Jakobson considera que essa equivalência na diferença, ou seja, a imensa variedade de articulações possíveis para expressar as mesmas ideias em diferentes idiomas, é o problema principal da linguagem e a principal preocupação da Linguística (JAKOBSON, 1975: $65)$.
} 
Fonseca, Rafael Schuabb Poll da - Tradução e adaptação de mangás: uma prática linguístico-cultural

Entretanto, a impossibilidade da tradução ideal, ou seja, daquela em que há a troca de uma mensagem por outra que the seja plenamente equivalente em outro idioma, é defendida por Vilém Flusser. Este escritor multilíngue, famoso por traduzir diversas vezes seus próprios textos para várias línguas, uma após a outra, alegando que em cada idioma o texto ganha um novo teor, afirma que a única tradução verdadeira é aquela empreendida pelo autor do texto a ser traduzido ${ }^{7}$ (BERNARDo 2002: 18).

Um dos maiores estudiosos de Flusser, Rainer Guldin, concorda com essa afirmação e compara o processo de tradução ao jogo conhecido como "telefone sem fio", estruturado da seguinte forma: um grupo de pessoas senta-se ao redor de uma mesa e uma delas elabora uma frase, porém, sem revelá-la aos demais. Em seguida, esse jogador sussurra essa frase para um de seus vizinhos o mais discretamente possível, que então sussura para a pessoa seguinte e assim por diante. A brincadeira termina quando a frase, após ser sussurrada de participante para participante, chega novamente aos ouvidos do jogador que a elaborou. Nesse momento, geralmente a locução está bastante modificada em relação à sua versão original, tornando-se, por isso, risível (idem: 18-19).

Sobre tal comparação, defendendo a impossibilidade da tradução ideal, ou seja, a intraduzibilidade fundamental das línguas, Guldin afirma:

Procedimento similar, agora com um texto escrito e regras ligeiramente alteradas, também é usado na prática é também usado na prática da tradução para refletir sobre o caráter do duplo vínculo (double-bind) de todos os processos de tradução: a (im)possibilidade de reconciliar fidelidade ao original com a necessidade de adaptá-lo ao contexto da nova língua, Essa espécie de experiência conduz em geral a uma aceitação do fracasso em processos de tradução, no que tange à adequação e ao rigor. Em especial, o retorno do texto traduzido ao estágio final, ao momento preciso da retradução, deixa exposta a incapacidade fundamental de qualquer tradução para recuperar o sentido original (idem: 19).

\footnotetext{
7 " (...) the only true translation is the one attempted by the author of the text to be translated", no original em inglês.
} 
Fonseca, Rafael Schuabb Poll da - Tradução e adaptação de mangás: uma prática linguístico-cultural

Em oposição à valorização defendida por Jakobson da propriedade da equivalência na diferença, Guldin afirma que Flusser, durante suas múltiplas traduções, não se focava em procurar por essa unidade na diferença, mas sim utilizar como princípio criativo as diferenças que existem de uma língua para outra. Uma vez que o próprio Flusser traduzia e retraduzia seus textos, ele dominava e direcionava completamente todo o processo de tradução, evitando as perdas não intencionais que ocorrem nos textos que são traduzidos de uma língua para outra cada vez por uma pessoa diferente. Nesse caso, ocorre o que a teoria da tradução tenta evitar: borra-se a fronteira entre tradução, paráfrase e reescritura. Porém, segundo Guldin, "desde que toda forma de tradução implica um ato de interpretação", essa tarefa à qual a teoria da tradução se propõe é praticamente impossível (idem: 21).

É importante para a realização da pesquisa aqui pretendida destacar que no método de escrita e autotradução de Flusser este não se foca no texto em si, mas nos pensamentos e motivações que levaram esse texto a ser produzido. A mecânica de seu trabalho consiste em possibilitar ao escritor distanciar-se do texto e a cada tradução acumular mais e mais pontos de vistas diferentes, gerando um texto final mais rico. Isso é viável em um texto de própria autoria, mas não em um escrito por outra pessoa. Afinal, uma vez que todo texto, em especial os artísticos, é intencionalmente estruturado de forma a comunicar ideias e informações que seu autor pretende transmitir, qualquer distúrbio que $\mathrm{o}$ tradutor e/ou adaptador provocar durante seu trabalho poderá trazer sérias consequências e dificultar ou mesmo impedir o bom entendimento do leitor.

No caso das histórias em quadrinhos, as traduções/adaptações mal desenvolvidas não se restringem apenas a gerar distúrbios de ordem linguística e cultural. Nessa mídia, em que os desenhos e os textos constituem, segundo Umberto Eco uma "linguagem muito articulada e de absoluta precisão" (ECo 2006: 131), observa-se também a influência negativa que esse tipo de problema pode gerar no componente artístico de uma obra. 
Fonseca, Rafael Schuabb Poll da - Tradução e adaptação de mangás: uma prática linguístico-cultural

No caso dos mangás, que comportam uma quantidade de texto sobreposicionado ainda maior por causa da ampla utilização de onomatopeias (cujas diversas tipografias possuem suas própria significações) e cujos textos originalmente são escritos em sentido vertical (o que faz com que os autores de mangás elaborem balões de texto também verticalizados), as interferências artísticas que a tradução/adaptação pode gerar são enormes e perceptíveis por qualquer leitor. Na grande maioria das edições brasileiras de mangás podemos encontrar, por exemplo, diversos balões que se tornam grandes demais para o texto em português e, portanto, escrito horizontalmente.

\section{Obstáculos presentes na tradução e adaptação de mangás}

Em palestra realizada no ano de 2008 no XIX Encontro Nacional de Professores Universitários de Língua, Literatura e Cultura Japonesa, Arnaldo Massato Oka, tradutor de diversos mangás publicados no Brasil pela editora JBC, comentou sobre seis aspectos que estão presentes nos mangás e se apresentam como problemas durante o processo de tradução e adaptação de mangás. São eles: sentido de leitura, citações, transliteração e adaptação de nomes próprios, ditados e trocadilhos, gramática e onomatopeias. ${ }^{8}$

Além dos seis aspectos reconhecidos como problemáticos por Oka, acrescentei a tradução de tradução, totalizando assim em sete obstáculos que devem ser superados pelos tradutores de mangás. Esses obstáculos servirão de base para toda a comparação argumentativa exposta neste trabalho em relação à tradução e adaptação oficiais adotadas no Brasil nos diversos exemplos de mangás que serão apresentados adiante.

\footnotetext{
${ }^{8}$ Oka designa os aspectos listados como problemas (OKA 2008: 178), mas optei por chamá-los de "obstáculos", uma vez que esta palavra transmite melhor a ideia de desafio a ser superado do que "problema", que carrega um aspecto significativo mais negativo.
} 
Fonseca, Rafael Schuabb Poll da - Tradução e adaptação de mangás: uma prática linguístico-cultural

\section{1 Sentido de leitura}

O sentido de leitura de uma publicação é um obstáculo sem solução, pois deriva da escrita e da cultura do seu país de origem. No caso dos mangás, a ordem é, obviamente, a adotada no Japão, ou seja, a leitura é feita da direita para a esquerda, sendo, assim, oposta à ordem comumente utilizada no Brasil, o que a leva a ser encarada como um elemento que afasta possíveis novos leitores. Por outro lado, para os consumidores mais aficionados a manutenção do sentido de leitura original da obra é símbolo de qualidade na publicação de um mangá.

As primeiras editoras que trouxeram os quadrinhos japoneses para o Brasil, provavelmente por acreditarem que a ordem de leitura japonesa poderia ser um empecilho para suas vendagens, publicaram-nos com a ordem de leitura típica ocidental. Foram os casos de Lobo Solitário (publicado no Brasil pela editora Cedibra, em 1988, e pela Sampa, em 1990), Akira (pela Globo, em 1990) e Crying Freeman (pela Sampa, em 1992), entre outras obras. Entretanto, mesmo com a decisão editorial de utilizar a ordem de leitura brasileira, esses mangás não conseguiram popularizar o gênero no país. No ano 2000, a editora Conrad começou a publicar mangás no Brasil mantendo a ordem de leitura japonesa. As primeiras obras trazidas pela editora foram Cavaleiros do Zodíaco e Dragon Ball, que, superando todas as expectativas, fizeram um enorme sucesso e desencadearam uma verdadeira invasão de mangás no mercado editorial brasileiro.

É interessante ressaltar que a iniciativa de manter o sentido de leitura japonês na publicação de Cavaleiros do Zodíaco e Dragon Ball não partiu da Conrad, mas sim da Shueisha, a editora japonesa que detém os direitos sobre esses dois mangás (NETO 2009: 17). Desde então a fidelidade à edição japonesa, com a manutenção do sentido de leitura oriental, passou a ser 
Fonseca, Rafael Schuabb Poll da - Tradução e adaptação de mangás: uma prática linguístico-cultural

requisito de boa publicação aos olhos dos consumidores e se tornou uma constante entre as séries que chegam ao Brasil.

A preocupação dos leitores de mangás com a publicação dessas obras em sentido de leitura oriental se explica por três motivos fundamentais:

- maior aproximação com a edição original japonesa;

- não inversão de onomatopeias (assunto que será desenvolvido adiante);

- não adulteração do universo criativo da história, uma vez que a publicação de um mangá em ordem de leitura ocidental resulta na total inversão dos desenhos, tranformando, por exemplo, pessoas destras em canhotas e viceversa.

\subsubsection{Página de aviso}

Apesar de que os leitores tenham se adaptado e superado a dificuldade do sentido inverso de leitura, quase todos os mangás ainda trazem avisos em sua última página - que seria a primeira, segundo a ordem de leitura ocidental - alertando ao consumidor que comece a leitura pelo outro lado da revista. Esse aviso, entretanto, é apresentado sob formas diferentes, de acordo com o mangá no qual estão inseridos.

No caso das primeiras histórias em quadrinhos japonesas lançadas em sentido oriental, havia explicações mais detalhadas sobre o sentido de leitura inverso ao brasileiro. Isso é natural, já que as editoras que publicaram esses mangás tinham enorme interesse em preparar os leitores, que ainda não estavam acostumados com essa peculiaridade dos mangás em relação às histórias em quadrinhos brasileiras e estrangeiras - mas ocidentais - que eram publicadas aqui até então. As páginas de avisos desses mangás também apresentavam um esquema de ordem de leitura, com a utilização de números e frases imperativas - frases de alerta e/ou de conselho (LIMA 2000: 233) -, como "Pare!" ou perguntas retóricas como "Vai começar pelo fim?". 
Fonseca, Rafael Schuabb Poll da - Tradução e adaptação de mangás: uma prática linguístico-cultural

No caso dos primeiros mangás publicados pela editora JBC, é interessante notar que, a página oposta à de avisos, ou seja, a página pela qual se inicia a leitura de uma publicação segundo o sentido japonês, apresentava elementos de confirmação - a saber, uma mão fazendo sinal de positivo e a frase “Comece a ler o seu mangá por aqui”.

No caso dos primeiros mangás publicados pela Conrad, além dos três elementos citados anteriormente (explicações mais detalhadas sobre o sentido oriental da história, esquema de ordem de leitura e frase de alerta para o leitor), as páginas de avisos apresentavam também um discurso de diferenciação entre mangás e outros tipos de quadrinhos, justificando elementos como a impressão em preto e branco e o estilo característico do traço dos desenhistas japoneses. Naturalmente, tal discurso era uma resposta pronta para questões sobre essas duas características que, assim como o sentido de leitura, poderiam refletir em um efeito de rejeição por parte de novos consumidores.

Com o passar do tempo, as páginas de avisos dos mangás publicados no Brasil passaram a reduzir as explicações sobre a ordem de leitura oriental, mas incluíram imagens de personagens da obra em questão em situação geralmente de espanto, irritação ou até mesmo de ataque, de acordo com a temática da série. Um exemplo disso é Kare Kano - as razões dele, os motivos dela, um mangá que tem elementos de humor. No caso dessa obra, a editora optou por criar uma "história” cômica na página de aviso, utilizando imagens da série.

Outras publicações mantiveram apenas a frase de aviso e a imagem de um personagem da série sem, porém, apresentarem um esquema de leitura. É o exemplo do mangá Hellsing. Nota-se também nesse caso a adequação entre a imagem escolhida e o conteúdo violento do mangá em questão. 


\subsubsection{Influência do sentido de leitura em "mangás" brasileiros}

Na última década, os mangás alcançaram um sucesso tão grande no Brasil que começaram a influenciar o surgimento de obras produzidas em território nacional e que buscam aliar a estética dos mangás japoneses a temáticas mais próximas da realidade brasileira. Os Estúdios Mauricio de Sousa, em parceria com a editora Panini, são responsáveis pelo exemplar de maior êxito entre os "mangás" brasileiros: a série Turma da Mônica J ovem [6]. A série está em seu volume de número 23 (edição de julho de 2010) e inclusive já influenciou outras obras, como Luluzinha Teen e sua Turma, da Pixel.

Embora se trate de um "mangá", 9 essa obra é estruturada no sentido comum no Brasil. 0 inusitado, porém, é que a última página de cada edição de Turma da Mônica J ovem apresenta avisos sobre sua ordem ocidental, com a justificativa de que a série foi assim publicada por causa de sua origem brasileira. É bastante interessante o fato de que a editora tenha a necessidade de utilizar uma página para esse alerta até mesmo em uma obra nacional, chegando ao ponto de colocar um esquema de leitura explicando esse sentido de leitura.

\footnotetext{
${ }^{9}$ Há muitos argumentos a favor ou contra o status de mangá dessa obra - e, como já foi dito anteriormente, em relação a qualquer outra obra produzida no Brasil e que se propõe como "mangá". Porém, como tal discussão demanda um espaço próprio e não cabe (tanto no sentido espacial quanto no sentido de pertinência) no presente trabalho. Neste momento, prefiro designar a série Turma da Mônica Jovem simplesmente como "mangá”, entre aspas.
} 


\subsubsection{Tategaki, a verticalização da escrita}

Outra dificuldade provocada pelo sentido de leitura à adaptação de mangás para a língua portuguesa é a verticalização da escrita nipônica. No Japão, a escrita tradicional é aquela em que os caracteres aparecem um em cima do outro, sendo assim chamada de tategaki ("tate" significa "vertical" e “gaki” vem do verbo “kaku”, que é “escrever”). Embora, por influência ocidental, haja no Japão algumas situações em que a escrita horizontal seja adotada, o tategaki continua sendo usado em muitos meios, como é o caso dos mangás, dos jornais e das revistas em geral.

A utilização do tategaki nas histórias em quadrinhos japonesas não é, em si, um obstáculo. O problema é que esse tipo de escrita demanda balões igualmente verticais, assim como a escrita ocidental exige balões horizontais. Desse modo, é comum que, no caso dos mangás publicados no Brasil, o texto se concentre na metade (da extensão vertical) do balão, sobrando bastante espaço abaixo e acima.

Os mangás são obras artísticas e, portanto, o caráter estético é inerente a eles. Assim, a desarmonia, em maior ou menor grau, gerada pela concentração do texto no meio dos balões das edições brasileiras dessas histórias em quadrinhos se configura como um elemento antiestético.

Um recurso bem interessante empregado pelas editoras brasileiras de mangás para solucionar a questão da verticalização da escrita japonesa é colocar o texto em português também no sentido vertical. Essa estratégia, porém, só funciona plenamente quando a tradução do texto do balão se resume a uma palavra. 
Fonseca, Rafael Schuabb Poll da - Tradução e adaptação de mangás: uma prática linguístico-cultural

\subsection{Citações}

Antes de desenvolvermos a análise sobre citações, é necessário esclarecer que considero aqui como citação qualquer nome, frase ou assunto que faça referência a pessoas famosas, filmes, músicas, livros, histórias em quadrinhos etc., sejam estas referências direcionadas a elementos do próprio Japão ou do exterior.

São dois os obstáculos provocados pelas citações: o primeiro é a necessidade de um tradutor/adaptador antenado à cultura pop japonesa e internacional e com conhecimento vasto sobre o universo nipônico em geral; o segundo é o fato de que o quadrinista japonês se preocupa que seu mangá seja de fácil leitura especificamente para os japoneses. Dessa forma, assim como podem ocorrer citações que sejam compreensíveis por todos os leitores (japoneses e estrangeiros) - como, por exemplo, uma citação à cantora Madonna ou ao célebre Leonardo da Vinci -, podem ocorrer também algumas muito intrínsecas à cultura japonesa, mas que estão distantes do entendimento por parte dos leitores do Brasil.

Cabe ao tradutor/adaptador considerar que citações necessitam ser esclarecidas para os consumidores brasileiros. Na edição brasileira do mangá Naruto, por exemplo, há toda uma preocupação em informar o leitor sobre palavras e elementos culturais japoneses citados na história, impedindo, assim, que ele fique perdido em alguns momentos. A editora Panini optou por colocar uma seção entitulada "Glossário", cujo número de páginas varia de edição para edição, no fim de cada volume, elucidando alguns termos. Apesar da explicação dessas palavras na própria página em que elas aparecem fornecer um respaldo cultural mais imediato, justifica-se a opção da editora, uma vez que alguns esclarecimentos são necessariamente longos e o espaço entre os quadrinhos de uma página são, em geral, pequenos. Acredito, entretanto, que as palavras que são explicadas no Glossário deveriam ser melhor destacadas nos balões em que aparecem, ao invés de serem 
Fonseca, Rafael Schuabb Poll da - Tradução e adaptação de mangás: uma prática linguístico-cultural

simplesmente grafadas em itálico. A melhor opção seria colocar um número entre colchetes ao lado da palavra, indicando assim a sua posição no "glossário" (ou como quer que se chame este tipo de seção em cada mangá). Os termos que são explicados no glossário são os mais variados possíveis: geografia, culinária, videogames, medicina, sistema de educação japonesa etc.

A questão das citações também está presente nas partes de free talking ${ }^{10}$ dos mangás. Como já foi dito neste trabalho, cada vez mais as editoras brasileiras de quadrinhos japoneses têm se comprometido com a fidelidade ao produto original e, assim, é comum que as partes de free talking sejam traduzidas e mantidas nas edições nacionais. A questão é que, nesses espaços, o autor tem liberdade para falar sobre assuntos em gerais e isso acarreta um grande número de citações: lugares que o quadrinista visitou, jogos de videogames, artistas, outros mangás etc. Algumas dessas citações são explicadas pelo próprio autor, mas outras não, provavelmente por ele considerar como informações de conhecimento dos leitores (japoneses).

\subsection{Transliteração e adaptação de nomes próprios e termos japoneses}

Nomes próprios precisam ser escritos em letras romanas e termos japoneses que não podem ser traduzidos precisam ser adaptados ou transliterados e, neste segundo caso, explicados assim como as citações (no capítulo anterior).

Em relação aos nomes próprios, as fontes de maiores complicações para os tradutores/adaptadores são o prolongamento e as diferenças entre os

\footnotetext{
${ }^{10}$ Muito comuns nos quadrinhos japoneses, o free talking é um espaço no qual o autor tem a possibilidade de conversar com os leitores de sua obra. Muitas vezes, o assunto gira em torno das dificuldades de se desenhar uma série de mangás - tempo curto, um incidente ou outro etc. - ou de hobbies do quadrinista.
} 
Fonseca, Rafael Schuabb Poll da - Tradução e adaptação de mangás: uma prática linguístico-cultural

caracteres que constam no alfabeto do português, mas não constam no silabário do japonês, como é o caso da letra “L”.

No caso do prolongamento, por exemplo, existe a prática, da qual eu discordo bastante, de se colocar um "H” depois de uma vogal para prolongála, principalmente quando em nomes próprios. Por exemplo, é o caso do nome de um personagem do mangá Cavaleiros do Zodíaco (publicado pela Conrad), cujo nome foi romanizado como “Dohko”, enquanto em japonês é “ドウコ” (“Douko").

Uma vez que os leitores brasileiros não têm obrigação de conhecerem as regras do idioma japonês, eu acredito que, embora me pareça mais natural, escrever "Douko" não sinalizaria de forma correta a sonoridade do nome, portanto, o ideal seria romanizar esse nome como "Dōko", com esse traço, chamado mácron, ${ }^{11}$ em cima da vogal prolongada. A romanização para prolongamentos nas demais palavras seguiria o mesmo método: "sensei" seria escrito "sensē" e "otousan" seria “otōsan".

Sobre a questão entre o "L" e o "R" do idioma japonês, acredito que deve-se chegar a um consenso sobre qual dos dois utilizar em nomes e termos genuinamente japoneses - nesse caso, a opção por " $R$ ” seria mais bem-vinda, uma vez que é a representação mais tradicional da coluna do “ら” (“ra”), do alfabeto japonês.

Por outro lado, é importante que haja uma investigação sobre a origem dos nomes que serão transliterados. Novamente citando o mangá Cavaleiros do Zodíaco, há um personagem francês cujo nome é inspirado no escritor Albert Camus. Em japonês, seu nome é escrito “カミュ” (“Kamyu”), que é a interpretação do silabário japonês para a pronúncia francesa do nome “Camus". Na edição brasileira, porém, o nome do personagem era escrito “Kamus”, ou seja, não era nem a versão escrita em japonês, nem a versão de origem.

\footnotetext{
11 o mácron é um sinal em forma de traço horizontal utilizado em algumas línguas, como o próprio latim, para indicar que a vogal por ele assinalada é longa.
} 
Fonseca, Rafael Schuabb Poll da - Tradução e adaptação de mangás: uma prática linguístico-cultural

Quanto a termos japoneses, acredito que a melhor opção, entre traduzir diretamente para o português ou colocar uma nota explicando, varia muito de caso para caso. No caso de uma palavra como battousai, por exemplo, é melhor manter o termo transliterado e colocar uma nota na própria página em que ele aparece, explicando que se trata de um mestre em saque de espada.

Por outro lado, me parece bastante desnecessário manter o termo "kansaiben" e explicá-lo com uma nota no final do mangá. Seria muito mais claro, especialmente para o leitor, se o tradutor/adaptador optasse por traduzir como "dialeto de Kansai" e explicar apenas "Kansai" em uma nota posterior.

\subsubsection{Caso dos títulos dos mangás}

Todo fã mais purista (ou conservador) detesta qualquer alteração em relação à edição original do mangá. No que diz respeito ao título de um mangá, a verdade é que o tradutor/adaptador não tem muito poder sobre sua escolha, que é determinada por imposição da editora japonesa do quadrinho, ou pela decisão da editora brasileira de tornar o título mais vendável, como deve ter sido o caso do mangá Samurai $X$, que originalmente se chama Rurouni Kenshin.

Recentemente, a editora Akita Shoten determinou que a JBC alterasse o logo do mangá Saint Seiya - The Lost Canvas, que era publicado até então com um logo no qual o destaque era para "Cavaleiros do Zodíaco", nome pelo qual a série ficou famosa no Brasil. A editora japonesa exigiu que o destaque fosse para o nome original do mangá - Saint Seiya. 


\subsection{Ditados e trocadilhos}

Um dos elementos mais complexos na adaptação de mangás é a presença de ditados e trocadilhos. Essa dificuldade se deve à relação muito íntima entre esses ditados e trocadilhos com a cultura ou a língua japonesas. Muitas vezes é impossível encontrar um correspondente exato para traduzir essas expressões, portanto acredito que seja muito mais válido explicar o jogo de ideias e/ou palavras que está presente.

\subsection{Gramática}

O obstáculo gramatical se configura pela estrutura frasal diferenciada do japonês em relação ao português, em especial no que diz respeito à posição do verbo e do objeto. Essa característica gera dificuldade aos tradutores/adaptadores, principalmente quando há uma frase extensa e dividida entre diferentes quadrinhos.

Além disso, com a diferença na posição entre verbo e objeto se torna complexo manter a carga dramática e o suspense em certos momentos na edição em português. Um exemplo clássico desse tipo de dificuldade é a frase "Anata wo aishiteru", que pode ser traduzida como "eu te amo", em português. Para ficar mais claro, imaginemos um mangá em japonês cuja certa página termine com dois personagens se encarando e um deles dizendo "Anata wo..." - "você", mas na função de objeto. O leitor cria enorme expectativa para saber o que acontecerá na página seguinte, como a frase se concluirá.

Porém, se um tradutor/adaptador apenas traduzir a frase para o português, provavelmente, seguindo a ordem frasal natural da língua portuguesa, essa mesma página terminará com “( $\mathrm{Eu})$ amo...”, destruindo todo o suspense que o quadrinista quis criar para a cena. Afinal, com dois 
Fonseca, Rafael Schuabb Poll da - Tradução e adaptação de mangás: uma prática linguístico-cultural

personagens se encarando e um deles dizendo “Eu amo..." não é difícil imaginar como terminará a frase na próxima página.

Nesse caso, seria melhor traduzir de forma que o verbo (que neste caso é o grande elemento a ser revelado) fique na página seguinte. Uma boa opção é manter na primeira página “Eu..." e na posterior "te amo”, pois tanto o sentido como o suspense são mantidos, tais quais na versão original.

\subsection{Onomatopeias}

A tradução de onomatopeias no processo de adaptação do japonês para o português é muito mais complexa do que ocorre com a maioria das obras cuja língua original é outra. Isso ocorre porque a língua japonesa possui a tradição de uma ampla utilização de onomatopeias na fala e na escrita - na língua portuguesa seu número é bem mais reduzido. Em decorrência disso, os tradutores são muitas vezes obrigados a inventar onomatopeias que não são dicionarizadas em português.

\subsubsection{Diferenças entre as onomatopeias do português e do japonês}

Em português, chama-se onomatopeia a atribuição da capacidade que certos sons linguísticos, ou seu agrupamento, têm para imitar ou sugerir determinados ruídos (LIMA 2000: 479). Desse modo, o uso de onomatopeias nessa língua ocorre com a função de indicar um certo som. Podemos citar, como exemplo, "miau” para sugerir miado de gato.

No caso da língua japonesa, porém, além das onomatopeias que funcionam como sinalizadores de sons, há também aquelas que são utilizadas para a sugestão de certa situação, chamadas, em japonês, de gitaigo e 
Fonseca, Rafael Schuabb Poll da - Tradução e adaptação de mangás: uma prática linguístico-cultural

gijougo e, em português, de mímesis (LeITÃo 2008: 375). Há no japonês, por exemplo, “ごごごご” ou “ゴゴゴゴ”, lê-se “gogogogo”, que indica uma atmosfera ameaçadora, e até mesmo uma onomatopeia para expressar ausência de sons no ambiente da cena: “しーん” ou “シーン”, lê-se "shīn”, (Nihongo Resources, http://www.nihongoresources.com/sfxbrowse, acessado em 15/6/2010).

Para falantes de um idioma como o português, no qual as onomatopeias são utilizadas exclusivamente para indicar sonoridade e, desse modo, assemelham-se a um registro gráfico do som que representam, pode ser complexo o entendimento do uso das gitaigo e gijougo japonesas. Entretanto, é importante ressaltar que essa concepção de onomatopeias enquanto vocábulos motivados (ou seja, mera representação gráfica do som que se ouve) não é um consenso entre os estudiosos de línguas. Para a corrente linguística do Estruturalismo, por exemplo, segundo Saussure:

Quanto às onomatopéias autênticas (aquelas do tipo glu-glu, tic-tac, etc.), não apenas são pouco numerosas, mas sua escolha é já, em certa medida arbitrária, pois que não passam de imitação aproximativa e já meio convencional de certos ruídos. Além disso, uma vez introduzidas na língua, acabam envolvidas na mesma evolução fonética, morfológica, etc., que sofrem as outras palavras: prova evidente de que se perdeu parte de seu caráter primitivo para adquirir o de signo linguístico comum, que não é motivado. (SAUSSURE 1969: 9495)

A partir do fragmento acima, torna-se perceptível que a compreensão de onomatopeia enquanto simples registro gráfico de uma sonoridade é um conceito muito limitado. Quando consideramos as gitaigo e gijougo japonesas, isso se torna ainda mais evidente. 


\subsubsection{0 elemento artístico}

Nas histórias em quadrinhos, além do valor linguístico, as onomatopeias também possuem um aspecto artístico, uma vez que podem apresentar variações de volume, tridimensionalidade e tamanho dos grafemas. Muitas vezes este segundo aspecto, inteiramente visual, se sobrepõe ao primeiro (LEITÃo 2008: 374).

Nos mangás, a representação gráfica das onomatopeias é totalmente integrada ao desenho, harmonizando-se e podendo interagir com os personagens e/ou cenário presentes em um quadrinho.

O estilo da grafia de uma onomatopeia pode funcionar como recurso suplementar para realçar seu valor representativo. 0 estilo dos caracteres de uma onomatopeia podem indicar diversos aspectos, variando de contexto para contexto, como, por exemplo, gradação de som.

Outro recurso artístico que pode ser empregado com o uso de onomatopeias é a sua grafia servindo de apontamento para a fonte do som que ela está representando.

\subsection{Tradução de tradução}

A tradução em si já é uma versão de um texto e não uma cópia fiel e perfeita em outro idioma. Quando a tradução é feita tendo como base outra tradução e não o próprio original, os problemas gerados durante o processo tendem a se multiplicar: torna-se a versão de uma versão do original.

Assim como os primeiros mangás que foram publicados no Brasil, no fim dos anos 80 e começo dos 90, até hoje alguns quadrinhos japoneses que chegam aqui usam como referência edições que não são japonesas, mas sim 
Fonseca, Rafael Schuabb Poll da - Tradução e adaptação de mangás: uma prática linguístico-cultural

traduções das edições japonesas. Utilizarei como exemplos dois mangás muito populares no Brasil: Caval eiros do Zodíaco e Naruto.

A edição brasileira de Cavaleiros do Zodíaco tem como ponto de partida a edição francesa. Isso explica, por exemplo, por que a onomatopeia “シーン” ficou com a tradução "silence", que é "silêncio" em francês, na publicação brasileira. A revisão do mangá não percebeu o deslize, nem mesmo quando fizeram uma segunda edição "corrigindo" os problemas de tradução e de adaptação da primeira versão, e o erro foi mantido.

A seguir, um exemplo de dificuldade gerada pela tradução de tradução aliada à problemática da adaptação de nome próprio. Na França, o personagem “ルネ” (lê-se “rune”), ficou conhecido como “Renê". A tradução brasileira adotou "Lune", uma das possibilidades - já que a ausência do "L" de início de sílaba no Japonês possibilita a leitura de “ル” tanto como “ru” quanto como "lu" -, mas deixou passar para a publicação a alternativa francesa, "Renê", em uma cena em que o referido personagem aparece (esse engano, entretanto, foi corrigido na segunda edição brasileira do mangá).

Outro problema decorrente da tradução de tradução de mangás é o fato de que a versão com que se tem que trabalhar pode já conter edições e censuras na imagem e/ou no texto. No caso de Naruto, os arquivos com que a editora Panini trabalha vêm dos Estados Unidos e contêm esses dois tipos de problemas, que desagradam muito aos fãs.

0 problema seguinte se refere à censura e levou a editora Panini a fazer uma segunda edição de Naruto com esse tipo de problema corrigido (no caso das onomatopeias isto não foi possível porque, segundo contrato com a editora japonesa do mangá, a Panini é obrigada a utilizar os arquivos digitais norte-americanos).

Voltando a Cavaleiros do Zodíaco, este mangá também sofreu com a censura (no caso, na edição francesa) e, assim como aconteceu com Naruto, teve uma segunda edição publicada pela editora Conrad, com a correção de vários dos muitos erros presentes na primeira versão. Em alguns momentos da 
Fonseca, Rafael Schuabb Poll da - Tradução e adaptação de mangás: uma prática linguístico-cultural

trama, a censura imposta pela edição francesa àquele mangá levou à alteração de falas dos personagens e do teor cômico originalmente empregado pelo autor.

\section{Conclusão}

O processo de tradução e de adaptação de mangás para o português ainda não possui um estudo aprofundado no Brasil. Apesar dos mangás apenas terem obtido sucesso há aproximadamente uma década atrás e, portanto, serem itens relativamente recentes no país, é urgente a necessidade de se formar profissionais qualificados para exercitar a árdua tarefa de traduzir e adaptar as particularidades artísticas e midiáticas dos mangás.

Em minha pesquisa, encontrei muitas situações em que os tradutores, adaptadores e revisores pareceram ignorar as falhas que thes saltavam aos olhos e permitiram que o material fosse publicado de forma não ideal. Isso ficou ainda mais claro no caso dos mangás que tiveram uma segunda edição como alternativa para corrigir os erros da primeira, e que, mesmo assim, ainda apresentaram diversos problemas.

É necessário registrar aqui que, por outro lado, também encontrei boas escolhas por parte desses profissionais. Porém, como o presente trabalho buscou registrar os obstáculos para a tradução/adaptação de histórias em quadrinho japonesas para o português, e como esses obstáculos podem dificultar a compreensão e captação dos recursos originalmente empregados pelos autores de mangás, me concentrei nos problemas que encontrei na edição brasileira dessas obras. 


\section{Referências bibliográficas}

BARTHES, Roland. Elementos de semiologia. 13. ed. São Paulo: Cultrix, 2006.

BernaRdo, Gustavo. As margens da tradução. Rio de Janeiro: Caetés, 2002.

Eco, Umberto. Apocalípticos e integrados. 6. ed. São Paulo: Perspectiva, 2006.

JAKOBSON, Roman. Linguística e comunicação. 10. ed. São Paulo: Cultrix, 1975.

LeITÃo, Renata Garcia de Carvalho. "As Onomatopéias japonesas e suas traduções/adequações nos manga traduzidos para o português". In: Anais do XIX encontro nacional de professores universitários de língua, literatura e cultura japonesa. Rio de Janeiro: Gráfica UFRJ, 2008.

LIMA, Rocha. Gramática normativa da língua portuguesa. 39. ed. Rio de Janeiro: José Olympio, 2000.

LUYEN, Sonia M. Bibe. Mangá: o poder dos quadrinhos japoneses. 2 ed. São Paulo: Hedra, 2000.

. (2001-2002) "Onomatopeias e mímesis no mangá: a estética do som”. In: Revista USP, n. 52, São Paulo CCS-USP, dez/jan/fev 20012002, p. 176-188.

MOLINÉ, Alfons. 0 grande livro dos mangás. São Paulo: JBC, 2004.

NAGADO, Alexandre. Almanaque da cultura pop japonesa. São Paulo: Via Lettera, 2007.

Neto, Guilherme. Mangás: uma leitura de jovens cariocas e paulistas. Rio de Janeiro, 2009.

OKA, Arnaldo Massato. "Tradução e adaptação de mangás para o português". In: Anais do XIX encontro nacional de professores universitários de língua, literatura e cultura japonesa. Rio de Janeiro: Gráfica UFRJ, 2008.

SATo, Cristiane Akune. Japop - o poder da Cultura Pop J aponesa. São Paulo: NSP Hakkosha, 2007.

SAUSSURE, Ferdinand de. Curso de linguística geral. São Paulo: Cultrix, 1969. 


\section{Referências em sites da internet}

E o Brasil conheceu os mangás...

Disponível em: <http://www.conexaoaluno.rj.gov.br/especiais-17b.asp>. (07/5/2010).

Mangá

Disponível em: <http: //www.japaoonline.com.br/pt/manga2.htm>. (07/05/2010).

Nihongo Resources

Disponível em:

<http://www.nihongoresources.com/dictionaries/onomatopoeia.html>. (15/06/2010).

Os estilos de escrita japonesa

Disponível em: <http://www.linguajaponesa.com.br/estilos-de-escritajaponesa.html>. (20/05/2010). 